\title{
Presence of HBV-DNA in Cord Blood Is Associated with Spontaneous Preterm Birth in Pregnant Women with HBeAg-Negative Chronic Hepatitis B Virus Infection
}

\author{
Ioannis S. Elefsiniotis ${ }^{a}$ Miltos Papadakis ${ }^{b}$ George Vlachos $^{b}$ Elena Vezali ${ }^{a}$ \\ Konstantinos Tsoumakas ${ }^{a}$ George Saroglou ${ }^{a}$ Aristidis Antsaklis ${ }^{b}$ \\ a University Department of Internal Medicine, Hepatology Unit, Elena Venizelou Hospital, and \\ bUniversity Department of Obstetrics and Gynaecology, Alexandra Hospital, Athens, Greece
}

\section{Key Words}

Hepatitis B · HBV-DNA • Cord blood • Pregnancy •

Preterm birth

\begin{abstract}
Spontaneous preterm birth is the leading cause of perinatal morbidity and mortality. In this study the spontaneous preterm birth rates in a group of hepatitis $B$ e antigen ( $\mathrm{HBeAg}$ )negative chronic hepatitis $B$ virus (HBV)-infected pregnant women without known risk factors for preterm delivery as well as the role of maternal laboratory data and hepatitis $B$ surface antigen/HBV deoxyribonucleic acid (HBV-DNA) in cord blood in respect to preterm labour were evaluated. 138 consecutive HBeAg-negative chronic HBV-infected pregnant women were evaluated during the perinatal period. Serum HBV-DNA was determined by using the Cobas Amplicor HBV Test in both maternal and cord blood samples. 102 women were finally evaluated ( 36 were excluded) and 15 of them (14.7\%) had spontaneous preterm birth. A significant association between spontaneous preterm birth and HBVDNA in cord blood was observed ( $p=0.007)$. HBV-DNA positivity in cord blood was significantly associated with maternal HBV-DNA levels ( $p=0.002$ ). The relative risk of HBV-DNA in cord blood was 6.43 times higher among women with se-
\end{abstract}

rum HBV-DNA $\geq 10,000$ copies/ml and lymphocyte count $<1,500$ compared to those with all the other combinations of both parameters $(p=0.001)$. In conclusion, the presence of HBV-DNA in cord blood is significantly associated with spontaneous preterm birth in chronic HBV-infected pregnant women. Women with HBV-DNA $\geq 10,000$ copies/ml and lymphocyte count $<1,500$ during the perinatal period have a higher probability of HBV-DNA in their cord blood.

Copyright $\odot 2011$ S. Karger AG, Basel

Preterm birth is the leading cause of perinatal morbidity and mortality in developed countries. The frequency of preterm births is about $12-13 \%$ in the USA and $5-9 \%$ in many other European and developed countries of the world. Spontaneous preterm births account for about $80 \%$ of preterm births and are considered to result from multiple causes including maternal infections or inflammations, uteroplacental ischemia or haemorrhage, uterine overdistension, stress and other immunologically mediated processes. Several maternal risk factors, pregnancy history and characteristics as well as a great number of genetic, environmental and social factors have been associated with spontaneous preterm births, but a precise mechanism cannot be established in most cases $[1,2]$.

\section{KARGER}

Fax +4161306 1234

E-Mail karger@karger.ch

www.karger.com (c) 2011 S. Karger AG, Basel

0300-5526/11/0545-0300\$38.00/0

Accessible online at:

www.karger.com/int
Ioannis $\mathrm{S}$. Elefsiniotis, $\mathrm{MD}, \mathrm{PhD}$

Carchidonos 9

A. Glyfada

GR-16562 Athens (Greece)

E-Mail ielefs@nurs.uoa.gr 
Maternal infection is a frequent and important risk factor leading to preterm birth basically due to activation of the innate immune system [3-5]. Maternal bacterial infections have been extensively studied in relation to preterm deliveries [3-5], whereas the association between viral infections and preterm births is not yet fully resolved. There are conflicting data about the relevance of human immunodeficiency virus (HIV), herpes simplex virus, adenovirus, parvovirus, hepatitis $\mathrm{C}$ virus (HCV) and hepatitis $B$ virus (HBV) infections to preterm birth and the evidence provided seems insufficient to draw definite conclusions [3].

The impact of maternal chronic HBV infection on pregnancy outcome has been evaluated in some studies, mainly from South-Eastern Asia [6-8], but their results are controversial. Data concerning the impact of maternal chronic HBV infection on pregnancy outcome among European pregnant women, in whom the hepatitis B e antigen ( $\mathrm{HBeAg}$ )-negative form of the infection dominates, are limited. Moreover, to our knowledge, there are no data concerning the role of maternal serum HBV deoxyribonucleic acid (HBV-DNA) levels during the perinatal period and/or HBV-DNA in cord blood in relation to preterm delivery in these women.

In this study the spontaneous preterm birth rates in a group of HBeAg-negative chronic HBV-infected pregnant women without known risk factors for preterm delivery were evaluated. Moreover the role of maternal haematological, biochemical and virological data during the perinatal period as well as the role of hepatitis $\mathrm{B}$ surface antigen (HBsAg) and/or HBV-DNA in cord blood in respect to preterm labour were examined.

Between July 2005 and December 2007 a total of 138 chronic HBV-infected pregnant women who consecutively gave birth at the University Departments of Obstetrics and Gynaecology of the Alexandra Hospital and the Elena Venizelou Maternal and Perinatal Hospital of Athens were clinically, haematologically, serologically and virologically evaluated during the perinatal period. HBsAg, HBeAg, antibody to HBeAg, antibody to hepatitis $B$ core antigen and antibody to hepatitis B surface antigen were detected at delivery using routine commercially available enzyme immunoassays (Abbott Laboratories, Abbott Park, Ill., USA). Routine haematological and biochemical tests were performed using automated techniques.

A total of $2.0 \mathrm{ml}$ serum was obtained at delivery from chronic HBV-infected women and the samples were kept at $-80^{\circ}$ until measurement. Viral load was determined by using the commercially available Cobas Amplicor HBV

HBV-DNA and Spontaneous Preterm Birth
Test (lower limit of quantification: 300 copies $/ \mathrm{ml}$ ). Maternal serum HBV-DNA levels $\geq 10,000$ copies/ml were considered as high. Moreover, cord blood was obtained at the time of delivery and the samples were kept at $-80^{\circ}$ until further evaluation for the presence of HBsAg and/ or HBV-DNA, using the methods mentioned previously.

Spontaneous preterm birth was defined as spontaneous labour beginning prior to 37 weeks of gestation with or without rupture of membranes. Pregnant women with a known history of preterm birth, women with non-singleton pregnancy, women with known pregnancy-related complications (diabetes, hypertension, preeclampsia, placenta haemorrhage, etc.), women with other known bacterial, fungal, parasitic or viral infections as well as those with the HBeAg-positive form of chronic HBV infection were excluded from the final analysis.

Written informed consent was obtained from all the women of our study population. The study was performed in accordance with the 1975 Declaration of Helsinki and was reviewed and approved by the Alexandra Hospital Ethics Committee.

The Shapiro-Wilk criterion was used for the assessment of normality. Not all variables did exhibit a normal distribution, and therefore nonparametric statistical tests were used. The median differences between two groups were evaluated by calculating the Mann-Whitney U statistic. Pearson's $\chi^{2}$ test was used in order to test for any associations between categorical variables. If more than $10 \%$ of the expected frequencies in the contingency tables were lower than 5, Fisher's exact test was used. Data were analyzed using STATA ${ }^{\mathrm{TM}}$ statistical software (version 9.0; Stata Corp., College Station, Tex., USA).

Thirty-six women were excluded from the final analysis, according to the exclusion criteria of the study, due to non-singleton pregnancy $(\mathrm{n}=16)$, diabetes of pregnancy $(n=8)$, cholestasis of pregnancy $(n=4)$, preeclampsia $(n=$ $2)$, recurrent urinary tract infections $(n=3)$ and $\mathrm{HBeAg}$ positive serological status $(n=3)$. Of the remaining 102 pregnant women with chronic $\mathrm{HBV}$ infection who were finally evaluated (median age $=27$ years) in our study 59 were from Albania, 15 were from Greece and 28 were from Eastern European countries (Russia, Bulgaria, Romania, and Serbia). Spontaneous preterm birth was observed in 15 (14.7\%) of them and was more frequent among Eastern European (28.57\%) and Albanian (10.16\%) women compared to Greek women (6.66\%), without being statistically significant $(\mathrm{p}=0.055)$. The clinical and laboratory characteristics of the study population according to the presence or absence of premature delivery are presented in table 1 . As observed from table 1, age as 
Table 1. Clinical and laboratory characteristics of the study population as well as virological and serological cord blood data according to the presence or absence of spontaneous preterm birth

\begin{tabular}{lccc}
\hline & With SPB $(\mathrm{n}=15)$ & Without SPB $(\mathrm{n}=87)$ & p value \\
\hline Age of mother, years & $30(6)$ & $26(12)$ & 0.096 \\
Birth weight, g & $2,550(1,202)$ & $3,440(500)$ & $<0.001^{*}$ \\
Hb, g/dl & $11.4(2.85)$ & $11.8(2.10)$ & 0.122 \\
WBC count & $9,500(4,600)$ & $11,200(4,900)$ & $0.025^{*}$ \\
Lymphocyte count & $1,357(708)$ & $1,740(774)$ & $0.006^{*}$ \\
Platelet count & $189,000(152,500)$ & $208,000(104,500)$ & 0.735 \\
AST, IU/ml & $25(22)$ & $21(9)$ & 0.337 \\
ALT, IU/ml & $17(56)$ & $14(8)$ & 0.178 \\
Available samples of maternal HBV-DNA & 9 & 67 & 0.478 \\
$\quad$ Positive cases & 7 & 42 & $0.007^{*}$ \\
Negative cases & 2 & 25 & \\
Available samples of cord blood HBV-DNA & 9 & 64 & 0.208 \\
$\quad$ Positive cases & 5 & 8 & \\
Negative cases & 4 & 76 & 27 \\
Available samples of cord blood HBsAg & 13 & 49 & \\
$\quad$ Positive cases & 2 & & \\
Negative cases & 11 & & \\
\hline
\end{tabular}

Continuous variables are presented as median values (interquartile ranges, 75 th-25th percentile), while categorical ones are presented as absolute numbers. Significant at ${ }^{*} \mathrm{p}<0.05$.

$\mathrm{SPB}=$ Spontaneous preterm birth; $\mathrm{Hb}=$ haemoglobin; $\mathrm{WBC}=$ white blood cells.

well as the laboratory data of the pregnant women in labour were comparable among those with and those without preterm birth, except for the absolute lymphocyte count in the peripheral blood, which was significantly lower in women who exhibited preterm delivery $(\mathrm{p}=$ 0.006).

Data concerning maternal serum HBV-DNA levels during the perinatal period were available in 76 chronic HBV-infected pregnant women. In 27 of them (35.5\%) HBV-DNA was undetectable ( $<300$ copies $/ \mathrm{ml})$, whereas in 49 women (64.5\%) HBV-DNA was detectable (table 1). The majority of pregnant women with detectable serum HBV-DNA exhibited values lower than 10,000 copies $/ \mathrm{ml}$ $(35 / 49,71.42 \%)$ and only $28.57 \%(14 / 49)$ had HBV-DNA $\geq 10,000$ copies $/ \mathrm{ml}$. Detectable HBV-DNA was observed in 42 of 67 (62.7\%) chronic HBV-infected pregnant women without preterm delivery and in 7 of $9(77.8 \%)$ chronic HBV-infected pregnant women with preterm delivery $(\mathrm{p}=0.478)$. Moreover, the median HBV-DNA value among chronic HBV-infected pregnant women who had preterm delivery $(7,680$ copies $/ \mathrm{ml})$ did not significantly differ from the median HBV-DNA value among chronic $\mathrm{HBV}$-infected pregnant women who did not exhibit preterm delivery $(2,130$ copies $/ \mathrm{ml}, \mathrm{p}=0.152)$. Preterm labour was recorded in 5/35 (14.28\%) women with serum HBV-
DNA $<10,000$ copies/ml and in 2/14 (14.28\%) women with serum HBV-DNA $\geq 10,000$ copies $/ \mathrm{ml}(\mathrm{p}=0.999)$.

Data concerning cord blood HBV-DNA and HBsAg were available in 73 and 89 chronic HBV-infected pregnant women, respectively. HBV-DNA was detectable in $13(17.8 \%)$ cord blood samples evaluated, whereas HBsAg was detectable in $29(32.6 \%)$ samples. HBsAg was detected in the cord blood of 2 of 13 (15.4\%) chronic HBV-infected women who exhibited preterm birth as well as in 27 of 76 (35.5\%) women who did not have preterm delivery $(\mathrm{p}=0.208)$. In contrast to HBsAg, HBV-DNA was detected in the cord blood of 5 of $9(55.6 \%)$ chronic HBVinfected pregnant women who had preterm birth and in only 8 of $64(12.5 \%)$ women who did not exhibit preterm labour ( $\mathrm{p}=0.007$ ), as shown in table 1 . The median cord blood HBV-DNA levels did not differ among chronic HBV-infected women with or without preterm labour (316 vs. 347 copies $/ \mathrm{ml}$, respectively, $\mathrm{p}=0.404$ ).

Cord blood HBV-DNA positivity as well as HBsAg positivity were significantly correlated with maternal viral load during the perinatal period. In particular, the median maternal serum HBV-DNA was significantly higher in women who had detectable HBV-DNA in their cord blood compared to those with undetectable HBVDNA in their cord blood (147,543 vs. 1,646 copies/ml, re- 
spectively, $\mathrm{p}=0.002)$. Chronic HBV-infected pregnant women with serum HBV-DNA $\geq 10,000$ copies/ml during the perinatal period exhibited a 5.8 times higher risk of HBV-DNA in their cord blood compared to women with serum HBV-DNA $<10,000$ copies/ml (7/14-50 vs. $3 / 35-8.57 \%$, respectively, $\mathrm{p}=0.003)$. Moreover, the median maternal serum HBV-DNA was significantly higher in women who had detectable HBsAg in their cord blood compared to those with undetectable HBsAg in their cord blood (6,475 vs. 1,157 copies/ml, respectively, $\mathrm{p}=0.025$ ).

In order to find prelabour predictors of the HBV-DNA in cord blood samples we combined the maternal viral load ( $<$ or $\geq 10,000$ copies $/ \mathrm{ml}$ ) with the absolute lymphocyte count $(<$ or $\geq 1,500)$ in women's peripheral blood. It is important to note that the vast majority $(19 / 21,90.5 \%)$ of pregnant women with serum HBV-DNA $<10,000$ copies/ml and absolute lymphocyte count $>1,500$ did not exhibit HBV-DNA positivity in their cord blood. On the other hand, the majority of women with serum HBVDNA $\geq 10,000$ copies $/ \mathrm{ml}$ and absolute lymphocyte count $<1,500(5 / 7,71.4 \%)$ exhibited HBV-DNA positivity in their cord blood. The relative risk of HBV-DNA in cord blood was 6.43 times higher in women with serum HBVDNA $\geq 10,000$ copies/ $\mathrm{ml}$ and absolute lymphocy te count $<1,500(5 / 7,71.4 \%)$ compared to women with all the other combinations of HBV-DNA and absolute lymphocyte count $(\mathrm{p}=0.001)$.

In this study a higher risk of spontaneous preterm labour in chronic HBV-infected women who exhibited HBV-DNA in their cord blood compared to women with undetectable HBV-DNA in their cord blood was observed. Moreover, cord blood HBV-DNA positivity was observed frequently in women with chronic HBV infection and high viral load (HBV-DNA $\geq 10,000$ copies/ml) as well as low absolute lymphocyte count $(<1,500)$ during the perinatal period. To our knowledge this is the first study in Europe which evaluates the role of HBeAg-negative chronic HBV infection on pregnancy outcome, taking into consideration the maternal as well as the cord blood data.

Although there are plenty of data concerning the perinatal transmission of the infection to neonates from chronic HBV-infected mothers, data concerning the impact of chronic HBV infection on pregnancy outcome are limited and controversial. Moreover, all the information on this subject comes from South-Eastern Asia, where the HBeAg-positive form of the infection and the HBV genotypes B and C dominate. In 1999, Wong et al. [8] concluded that the presence of HBsAg in pregnant women does not pose an additional risk for the pregnancy. Six years later, Tse et al. [6] in a case-control study concluded that HBsAg carriers have an increased risk of threatened preterm labour, possibly due to the chronic inflammatory state that was observed in these subjects. In this study a relatively high rate of preterm delivery $(14.7 \%)$ in chronic HBV-infected pregnant women compared to the rates of the overall pregnant population reported from European (5-9\%) and US (12-13\%) studies [1] was found, despite the exclusion of women with known risk factors for preterm birth. Additionally a significantly higher risk for preterm birth in $\mathrm{HBeAg-negative} \mathrm{chronic} \mathrm{HBV-in-}$ fected women with detectable HBV-DNA in their cord blood as well as in those with relatively low absolute lymphocyte count in their peripheral blood during the perinatal period was observed.

It is well known that HBsAg can be transferred through the placenta barrier in about one third of HBeAg-negative chronic HBV-infected pregnant women, but the clinical impact of this phenomenon on the intrauterine-transplacental or perinatal transmission of HBV infection and/or passive-active immunoprophylaxis failure does not seem to be important [9]. On the other hand, the presence of HBsAg and/or HBV-DNA in cord blood, a phenomenon that it is frequently observed in women with high serum HBV-DNA levels during the perinatal period, as observed in our study, may exaggerate the inflammatory response leading to certain obstetric complications. In this study $32.6 \%$ of $\mathrm{HBeAg}$-negative chronic $\mathrm{HBV}$-infected pregnant women had detectable HBsAg and $17.8 \%$ had detectable HBV-DNA in the cord blood samples evaluated. Many studies have shown that increased serum concentration of proinflammatory cytokines play an important role in premature labour or prelabour rupture of membranes and that subclinical infections (such as chronic HBV infection) may induce low-grade systemic inflammatory response $[4,5]$, which could be the possible explanation of our findings. This possible explanation of lowgrade inflammatory response, which could be mainly located in the amniotic cavity of chronic HBV-infected pregnant women, especially in those with detectable HBV-DNA in their cord blood, may also explain why preterm labour was significantly associated with the absolute lymphocyte count (the lower the absolute lymphocyte counts in women's peripheral blood, the higher the possibility of preterm delivery), a finding that needs further investigation. Microbial invasion of the amniotic cavity, either ascending from the vagina and the cervix or by retrograde spread though the fallopian tubes or via haematogenous dissemination through the placenta (as 
was possibly the case in our study), is frequently associated with intra-amniotic inflammation and foetal inflammatory response which has been linked to the onset of preterm labour [1-3]. Moreover, it is possible that the well-known pregnancy-related plasma volume expansion and serum dilution, especially during the third trimester of pregnancy, might significantly affect serum HBVDNA levels as well as serum AST/ALT levels, so neither parameter was significantly associated with spontaneous preterm birth in our study.

Limitations of the study are the absence of data concerning possible co-infections (HCV, HDV, HIV), other subclinical infections of the genitourinary tract and environmental and social factors (smoking, alcohol, pollution, nutrition, economical status, etc.) that could affect the final results. Due to the cross-sectional design of the study, we do not have information on the direction of causality of associations, although the impact of HBVDNA in cord blood on premature labour seems likely. Due to the relatively small sample size of the study population, no adjustment for inflation of type I error due to multiple comparisons was made. Moreover, the sensitiv- ity of the HBV-DNA assay used was not ideal. Despite these limitations we believe that this group of HBeAgnegative chronic $\mathrm{HBV}$-infected pregnant women with a relatively low risk for preterm delivery, who were evaluated in respect to maternal as well as cord blood data, and the advantages of the study, such as the use of a central laboratory where all serological and virological tests were performed using the same methods, outweigh the limitations.

In conclusion, the presence of HBV-DNA in cord blood is significantly associated with spontaneous preterm labour in $\mathrm{HBeAg}$-negative chronic $\mathrm{HBV}$-infected pregnant women. Women with HBV-DNA $\geq 10,000$ copies $/ \mathrm{ml}$ and absolute lymphocyte count $<1,500$ during the perinatal period have a higher probability of HBV-DNA presence in their cord blood.

\section{Acknowledgement}

The study was partially supported by the Hellenic Foundation of Gastroenterology.

\section{References}

1 Goldenberg RL, Culhane JF, Iams JD, Romero R: Epidemiology and causes of preterm birth. Lancet 2008;371:75-84.

$>2$ Romero R, Espinoza J, Kusanovic J, et al: The preterm parturition syndrome. BJOG 2006; 113:17-42.

3 Pararas MV, Skevaki CL, Kafetzis DA: Preterm birth due to maternal infection: causative pathogens and modes of prevention. Eur J Clin Microbiol Infect Dis 2006;25:562569.
4 Goldenberg RL, Hauth JC, Andrews WW: Intrauterine infection and preterm delivery. N Engl J Med 2000;342:1500-1507.

$\checkmark 5$ Menon R, Fortunato SJ: Infection and the role of inflammation in preterm premature rupture of the membranes. Best Pract Res Clin Obstet Gynaecol 2007;21:467-478.

$\checkmark 6$ Tse KY, Ho LF, Lao T: The impact of maternal HBsAg carrier status on pregnancy outcomes: a case-control study. J Hepatol 2005; 43:771-775.

7 Lao TT, Chan BC, Leung WC, Ho LF, Tse KY: Maternal hepatitis $\mathrm{B}$ infection and gestational diabetes mellitus. J Hepatol 2007;47:4650 .
$>8$ Wong S, Chan LY, Yu V, Ho L: Hepatitis B carrier and perinatal outcome in singleton pregnancy. Am J Perinatol 1999;16:485-488.

-9 Elefsiniotis IS, Papadakis M, Vlachos G, Daskalakis G, Saroglou G Antsaklis A: Clinical significance of hepatitis B surface antigen in cord blood of hepatitis B e antigen negative chronic HBV infected mothers. Intervirology 2009;52:132-134. 